\title{
Relation between stage, grade, proliferation, and expression of p53 and CD44 in adenomas and carcinomas of the colorectum
}

\author{
P A Jackson, M A Green, A Pouli, R Hubbard, C G Marks, M G Cook
}

\begin{abstract}
Aims-To investigate the changes in and relations among p53, CD44 and MIB-1 expression in adenocarcinomas of the colorectum and to determine whether these changes are progressive across the adenoma-carcinoma sequence.

Methods-Expression of p53 protein, CD44 adhesion molecule and MIB-1 proliferation antigen was detected using immunohistochemistry in 68 colorectal carcinomas and 32 colorectal adenomas. The staining characteristics were compared with degree of dysplasia in adenomas, and differentiation and Dukes' stage in carcinomas. Results were analysed and assessed using Spearman's rank correlation and independent $t$ tests.

Results-p53 staining was present in some adenomas and correlated with the degree of dysplasia. There was significantly more staining in carcinomas than adenomas and significant correlation between staining and Dukes' stage. CD44 staining was maximal in adenomas, diminished in carcinomas and was minimal in metastasising carcinomas. There was an inverse correlation between p53 and CD44 expression across the adenoma-carcinoma-metastasising carcinoma sequence. MIB-1 expression was highest in carcinomas but did not correlate with either p53 or CD44 expression.

Conclusions-There are progressive changes in p53, CD44 and MIB-1 expression in adenomas and carcinomas. $A$ combination of these tests may prove useful in assessing which patients with adenomas are at greatest risk of progressing to carcinoma.
\end{abstract}

( $f$ Clin Pathol 1995;48:1098-1101)

Keywords: CD44, MIB-1, p53, adenoma, carcinoma, colorectum.

CD44 is a transmembrane glycoprotein molecule expressed by many normal tissues, ${ }^{12}$ is involved in cell-cell and cell-matrix interactions and facilitates lymphocyte recirculation and activation. It is expressed as a standard form (CD44H) and as numerous splice variants (CD44v). It is also expressed more frequently in adenomas and carcinomas of the large bowel with the greatest expression in tumours with confirmed metastases. ${ }^{34}$ CD44 has been associated with proliferation rep- resented by areas of $\mathrm{Ki} 67$ activity, suggesting that it has a role in tumour cell growth, ${ }^{5}$ and has recently been associated with mutations in the p53 gene. ${ }^{6}$ Wild-type p53 is normally present in cells and acts in several ways; on binding to DNA it suppresses cell proliferation and DNA replication following damage, causing the cell cycle to halt in $G_{1}$ phase. p53 also induces apoptosis. Mutations in the p53 gene result in loss of normal p53 activity and the number of mutations increases as colorectal adenomas progress to carcinoma to metastatic carcinoma. ${ }^{78}$ Some studies have shown a trend but no significant correlation between p53 expression and progression of carcinoma. ${ }^{10}$ One study found a correlation between cancer progression and p53 cytoplasmic, but not nuclear, staining ${ }^{11}$ and indicated a trend with survival.

The prognosis of colorectal carcinoma is governed by diverse factors that include parameters based on careful pathological assessment such as grade and stage of disease. ${ }^{12-14}$ This study was undertaken to investigate the potential of CD44 and p53 immunohistochemistry in the assessment of colorectal carcinomas and adenomas.

\section{Methods}

Sixty eight specimens from 63 patients with colorectal carcinoma and 32 specimens from 26 patients with colorectal adenomas (three patients with familial adenomatous polyposis, 23 with sporadic adenomas, six of which were associated with carcinoma elsewhere in the colorectum), were collected prospectively and processed by standard techniques to paraffin wax, after fixation in neutral buffered formal saline for 24-48 hours.

Consecutive $3 \mu \mathrm{m}$ sections were stained with haematoxylin and eosin for histological diagnosis and with the following antibodies: CD44 (F10-44-2, Cymbus BioScience), p53 (Pab 1801, ICRF) and MIB-1 (Ki67, Immunotech International). Samples of normal colon adjacent to carcinoma and two samples from metaplastic polyps were also stained with each antibody. Sections were de-waxed in xylene and rehydrated. Antigen retrieval was enhanced by pretreating the slides in a microwave oven (Tecnolec T205T, $750 \mathrm{~W}$ ). Sections immersed in $10 \mathrm{mM}$ citrate buffer $\mathrm{pH} 6.0$ were heated in a microwave oven for a total of 25 minutes (10 minutes plus five minutes $\times 3$ ) and allowed to cool in the buffer for 30 minutes. Sections were immersed in TRIS buffered saline $(\mathrm{pH} 7 \cdot 6)$ for five minutes and then endogenous peroxidase 


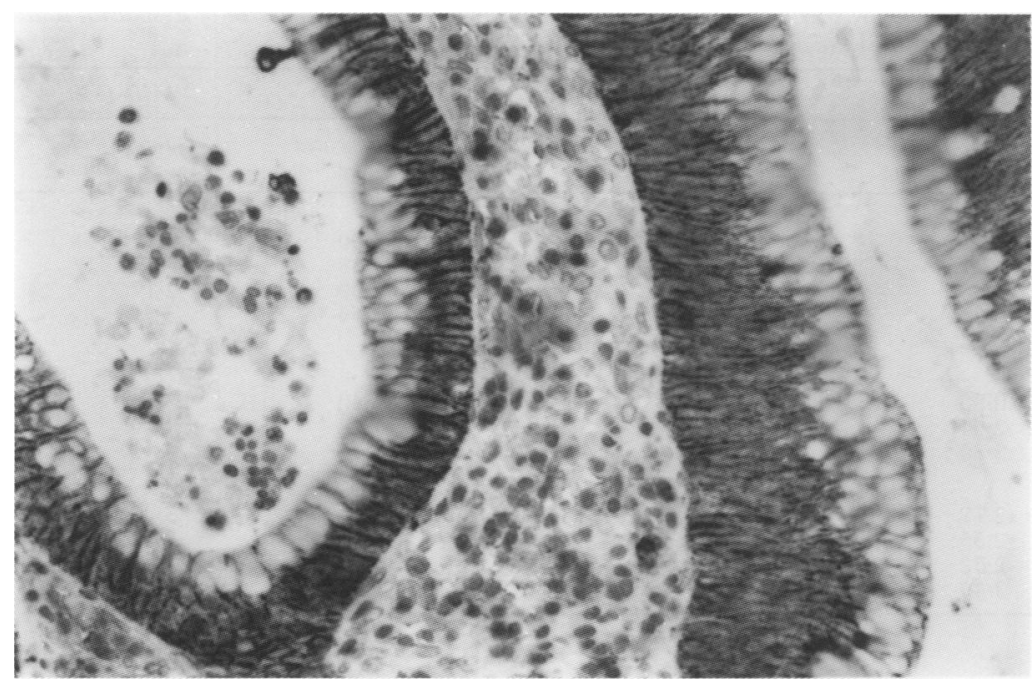

Figure 1 CD44 membrane staining of adenoma epithelium.

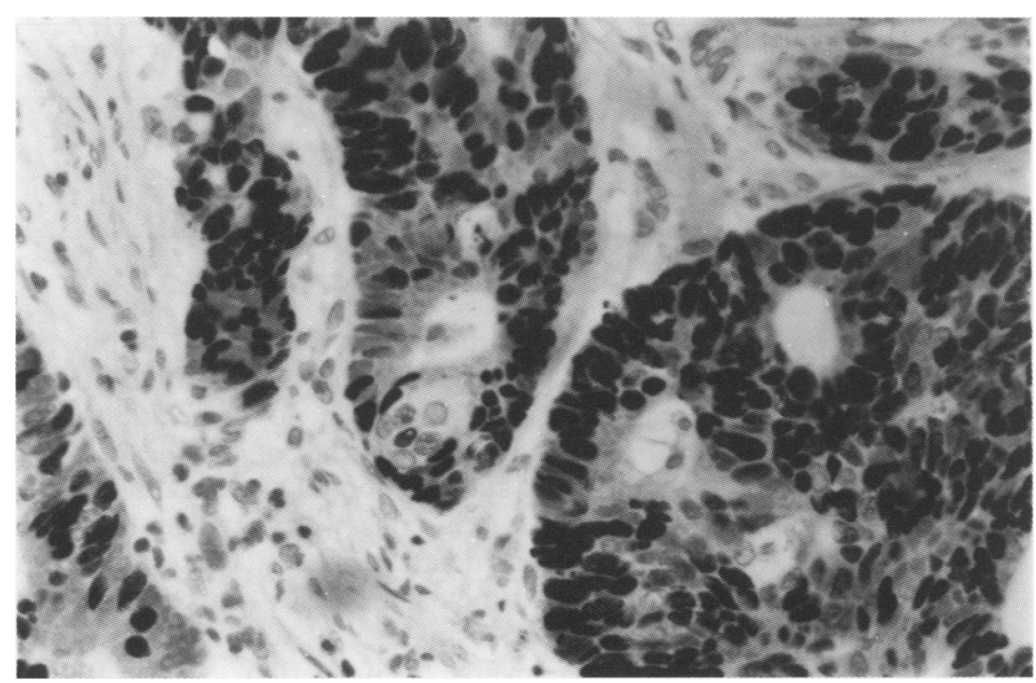

Figure 2 p53 nuclear staining in an adenocarcinoma.

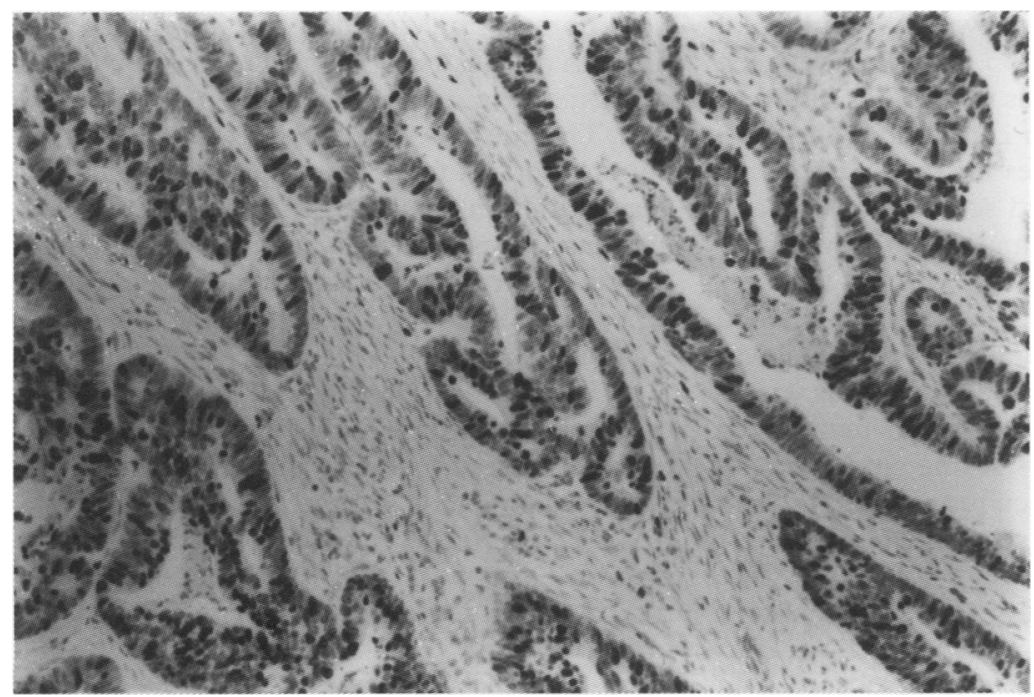

Figure 3 MIB-1 nuclear staining in an adenocarcinoma.

was blocked using 3\% hydrogen peroxide for five minutes before the slides were returned to TRIS buffer. Sections were stained using the avidin-biotin complex procedures as follows: sections were incubated initially with normal rabbit serum ( $20 \%$ in TRIS buffer for $20 \mathrm{~min}$ utes) and then with mouse antibody (dilution as per manufacturer's recommendation) for 30 minutes, rinsed, and immersed in TRIS buffer for five minutes. They were then incubated with biotinylated rabbit anti-mouse immunoglobulin (Dako, High Wycombe, UK) for 30 minutes, rinsed and immersed in TRIS buffer for five minutes, incubated with horseradish peroxidase labelled avidin-biotin complex (Dako) for 30 minutes, rinsed and immersed in TRIS buffer for five minutes. They were then incubated in diaminobenzidine (Sigma, Poole, Dorset, UK) for three minutes, rinsed and counterstained with Mayer's haemalum.

Stained sections were examined independently by two of the authors. CD44 positive staining was scored as follows: $1=$ weak membrane staining of less than half the cell surface; 2 =weak staining of half to all of the cell surface; $3=$ intense staining of all of the cell surface (fig 1).p53 positive nuclear staining was scored as light or intense (fig 2). MIB-1 positivity was scored as clear intense nuclear staining (fig 3).

All cases were reviewed simultaneously by the observers and a final score for each case agreed by discussion.

For analysis, the scores were organised into groups from 0 to 5 , based on the total percentage of cells staining positively: $1=1-20 \%$; $2=21-40 \% ; 3=41-60 \% ; 4=61-80 \% ; 5=81-$ $100 \%$. To determine whether the different intensities of staining for p53 and CD44 or only the total percentage of cells stained was important, a weighted score was devised which included a mathematical bias (\% cells of intensity $1 \times 1+\%$ cells of intensity $2 \times 2+\%$ cells of intensity $3 \times 3$ ). This was also divided into equal groups from 0 to 5 .

Spearman's rank correlation coefficient was used to assess the significance of changes within groups and an independent $t$ test to assess the significance of differences in means between groups.

Differentiation and stage of carcinomas and grade of dysplasia of adenomas were assessed on the haematoxylin and eosin stained sections, the grade of dysplasia in adenomas according to criteria discussed by Morson and Dawson. ${ }^{15}$

\section{Results}

Of the adenocarcinomas, six were well, 37 moderately and 25 poorly differentiated. Ten were Dukes' stage A, 28 Dukes' stage B and 30 Dukes' stage C. All of the adenomas were less than $25 \mathrm{~mm}$ in size and epithelial dysplasia was mild in three cases, moderate in 17 and severe in 12. The results are presented in table 1 which gives the scores for the different antibodies used, for adenomas according to degree of dysplasia and carcinomas according to Dukes' stage and degree of differentiation.

Normal mucosa and the metaplastic polyps did not stain with p53 antibody. In the adenomas staining for p53 was strongly positive in two cases, eight cases did not stain and 22 cases showed focal staining (1-20\% of cells 
Table 1 Mean scores on staining with CD44, p53 and MIB-1 for adenomas, according to the degree of dysplasia, and for carcinomas, according to Dukes' stage and the degree of differentiation

\begin{tabular}{|c|c|c|c|c|c|}
\hline \multirow[b]{2}{*}{ Lesion type } & \multicolumn{2}{|l|}{$p 53$} & \multicolumn{2}{|l|}{$C D 44$} & \multirow{2}{*}{$\begin{array}{l}\text { MIB-1 } \\
\text { Total \% of } \\
\text { cells staining }\end{array}$} \\
\hline & $\begin{array}{l}\text { Total \% of } \\
\text { cells staining }\end{array}$ & $\begin{array}{l}\text { Weighted } \\
\text { score }\end{array}$ & $\begin{array}{l}\text { Total \% of } \\
\text { cells staining }\end{array}$ & $\begin{array}{l}\text { Weighted } \\
\text { score }\end{array}$ & \\
\hline $\begin{array}{l}\text { Adenomas } \\
\text { mild dysplasia }(n=3) \\
\text { moderate dysplasia }(n=17) \\
\text { severe dysplasia }(n=12) \\
\text { Overall }(n=32)\end{array}$ & $\begin{array}{l}0.33 \\
0.71 \\
1.50 \\
0.97\end{array}$ & $\begin{array}{l}0 \cdot 33 \\
0 \cdot 71 \\
1 \cdot 42 \\
0 \cdot 94\end{array}$ & $\begin{array}{l}3 \cdot 67 \\
4 \cdot 00 \\
3 \cdot 75 \\
3 \cdot 87\end{array}$ & $\begin{array}{l}3 \cdot 00 \\
2 \cdot 88 \\
2 \cdot 00 \\
2 \cdot 56\end{array}$ & $\begin{array}{l}1 \cdot 67 \\
2 \cdot 53 \\
2 \cdot 17 \\
2 \cdot 31\end{array}$ \\
\hline $\begin{array}{c}\text { Carcinomas } \\
\text { Dukes'stage } \\
\text { A }(n=10) \\
\text { B }(n=28) \\
\text { C }(n=30)\end{array}$ & $\begin{array}{l}0 \cdot 80 \\
2 \cdot 54 \\
2 \cdot 80\end{array}$ & $\begin{array}{l}0 \cdot 80 \\
2 \cdot 04 \\
2 \cdot 37\end{array}$ & $\begin{array}{l}2 \cdot 10 \\
2.78 \\
1.72\end{array}$ & $\begin{array}{l}1.40 \\
1.82 \\
1.17\end{array}$ & $\begin{array}{l}3.63 \\
3.19 \\
3 \cdot 41\end{array}$ \\
\hline $\begin{array}{l}\text { differentiation } \\
\text { well } \\
\text { moderate } \\
\text { poor } \\
\text { Overall }(n=68)\end{array}$ & $\begin{array}{l}2 \cdot 17 \\
2 \cdot 35 \\
2 \cdot 52 \\
2 \cdot 40\end{array}$ & $\begin{array}{l}1 \cdot 67 \\
2.08 \\
1.96 \\
2 \cdot 00\end{array}$ & $\begin{array}{l}2 \cdot 17 \\
2 \cdot 70 \\
1 \cdot 43 \\
2 \cdot 21\end{array}$ & $\begin{array}{l}1 \cdot 17 \\
1.78 \\
1.09 \\
1.48\end{array}$ & $\begin{array}{l}3 \cdot 00 \\
3 \cdot 31 \\
3 \cdot 48 \\
3 \cdot 34\end{array}$ \\
\hline
\end{tabular}

Table 2 Mean scores on staining with CD44, p53 and MIB-1 for adenomas and non-metastatic (Dukes' stages $A$ and $B$ ) and metastatic (Dukes' stage $C$ ) carcinomas

\begin{tabular}{|c|c|c|c|c|c|}
\hline \multirow[b]{2}{*}{ Lesion type } & \multicolumn{2}{|l|}{$p 53$} & \multicolumn{2}{|l|}{$C D 44$} & \multirow{2}{*}{ 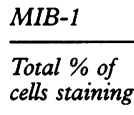 } \\
\hline & $\begin{array}{l}\text { Total \% of } \\
\text { cells staining }\end{array}$ & $\begin{array}{l}\text { Weighted } \\
\text { score }\end{array}$ & $\begin{array}{l}\text { Total \% of } \\
\text { cells staining }\end{array}$ & $\begin{array}{l}\text { Weighted } \\
\text { score }\end{array}$ & \\
\hline Adenomas $(n=32)$ & 0.97 & 0.94 & $3 \cdot 87$ & 2.56 & $2 \cdot 31$ \\
\hline $\begin{array}{l}\text { Carcinomas } \\
\text { non-metastatic } \\
\text { metastatic }\end{array}$ & $\begin{array}{l}2 \cdot 08 \\
2 \cdot 80\end{array}$ & $\begin{array}{l}1 \cdot 71 \\
2 \cdot 37\end{array}$ & $\begin{array}{l}2.59 \\
1.72\end{array}$ & $\begin{array}{l}1 \cdot 73 \\
1 \cdot 17\end{array}$ & $\begin{array}{l}3.31 \\
3.41\end{array}$ \\
\hline
\end{tabular}

staining positively in 11 cases). The positive cases were all tubular adenomas of less than $10 \mathrm{~mm}$ in diameter. There was no significant difference between scores based on the total percentage of cells staining and scores based on intensity and percentage of cells staining (weighted score). The scores correlated with the degree of dysplasia (Spearman's rho= $0.4358, \mathrm{p}<0.02)$. Of the carcinomas, 43 stained positively for $\mathrm{p} 53,34$ had a total percentage staining score of 3 (41-60\% positive staining) or above. There was a significant correlation of scores with Dukes' stage (Spearman's rho= $0.2539, \mathrm{p}<0.05)$. There was a significant difference in the level of p53 staining between adenomas and carcinomas $(t=3.56, p<0.001)$, with stronger staining in carcinomas than adenomas. Again, the values for total percentage staining and the weighted score were similar.

CD44 staining in normal mucosa was confined to the base of crypts and was not formally scored. Crypts in the metaplastic polyps stained positively for CD44. Staining for CD44 was present to some degree in all adenomas with a mean total percentage score of 3.9 when judged on percentage of cells staining and a mean weighted score of 2.6 when judged on intensity and percentage of cells staining. Comparable scores for carcinomas were $2 \cdot 2$ and $1 \cdot 5$. The difference in CD44 staining between adenomas and carcinomas was significant $(t=4 \cdot 11$, $\mathrm{p}<0.001$ ), with maximal staining observed in adenomas. The weighted score for CD44 staining based on intensity and percentage of cells staining was inversely correlated with the degree of dysplasia in adenomas (Spearman's rho $=0.3597, p<0.05$ ), and showed an inverse trend, but no correlation, with Dukes' stage. CD44 total percentage score was inversely correlated with overall differentiation of carcinoma
(Spearman's rho $=0.2913, \mathrm{p}<0.02$ ) despite the mean lower score for the six well differentiated carcinomas. There was no correlation with Dukes' stage or degree of dysplasia. The changes in staining for CD44 became clearer when the carcinomas were divided into two groups: non-metastatic cases (Dukes' stages A and B) and metastatic cases (Dukes' stage C) (table 2). Spearman's rank testing now showed strong inverse correlation (rho $=0.401$, $\mathrm{p}<0.001)$ between both methods of scoring CD44, with stronger staining for CD44 evident in non-metastatic carcinomas.

In normal mucosa MIB-1 staining was confined to crypts and was stronger in metaplastic polyps with a mean total percentage score of $2 \cdot 0$. The mean MIB- 1 score was $2 \cdot 3$ for adenomas and 3.4 for carcinomas. MIB-1 staining varied marginally between the different adenomas or carcinomas, but the variation in staining intensity on comparing carcinomas and adenomas was significant $(t=4 \cdot 26$, $\mathrm{p}<0.001$ ).

p53 expression was inversely correlated with that for CD44 on progression from adenoma to carcinoma to metastasising carcinoma (total percentage of cells staining: Spearman's rho $=$ $0.2497, p<0.02$; weighted score: Spearman's rho $=0.2289, \mathrm{p}<0.05$ ), but there was no significant change in the intensity of p53 expression between non-metastatic and metastatic carcinomas $(t=1 \cdot 43, p>0 \cdot 15)$.

\section{Discussion}

As can be seen from the results of this study, the intensity of p53 expression increased as the adenoma-carcinoma sequence progressed. Expression of p53 was uncommon in adenomas, but when present correlated with the 
degree of dysplasia, confirming the results of Scott et $a l^{7}$ As previously shown by Mulder et $a l,{ }^{6}$ there was a correlation between p53 expression and tumour progression; however, in our study the expression of p53 increased in intensity in Dukes' stage C carcinomas whereas in the study by Mulder et al p53 expression tapered off. We found that p53 was strongly expressed in some relatively small tubular adenomas $(5-10 \mathrm{~mm})$ suggesting that $\mathrm{p} 53 \mathrm{ex}-$ pression in adenomas may be an indicator of increased malignant potential over and above the usual morphological markers of tumour progression, such as villous type and large size. ${ }^{16}$ Strong expression of p53 ( $>30 \%)$ is specific for gene mutation whereas weak expression $(<30 \%)$ may represent normal unaltered wildtype p53. ${ }^{17}$ In our study low p53 scores always represented less than $5 \%$ of cells staining and usually less than $1 \%$ in both adenomas and carcinomas. Because of this and the correlation between our two scoring systems we feel that the percentage of cells staining is as important as the intensity of staining, and that either scoring system is valid. This may be important considering that weak p53 staining is fixative dependent, ${ }^{18}$ suggesting that assessments of p53 staining should be based on high intensity staining alone.

As in previous studies, ${ }^{15}$ CD44 was expressed more strongly in adenomas than in carcinomas. The weighted scoring system was biased to increase the effects of intensity of staining and showed the best association with dysplasia in adenomas. The effect of this scoring system, however, was reduced across the adenoma-carcinoma sequence. Similar findings were noted when high intensity staining was analysed separately. It seems likely that with CD44, both the intensity and percentage of cells stained is greatest in adenomas, and then on progression to carcinoma, overall CD44 expression decreases mainly due to a drop in the numbers of lightly stained cells (intensity 1). Our finding that CD44 staining decreases on progression to carcinoma differs from the findings of others, ${ }^{346}$ although scoring systems vary and few papers take intensity of staining into account. The increase in CD44 expression in metastasising carcinomas (Dukes' stages C and D) seems to be more pronounced with the CD44 splice variant V6. ${ }^{146}$ As yet, however, there is a dearth of information regarding the relations among the standard form of CD44 and its splice variants.

We noted that although CD44 and MIB-1 were coexpressed in the crypts in the normal controls and in two metaplastic polyps, we found no correlation between MIB-1 and CD44 expression in adenomas and carcinomas. MIB-1 expression increased significantly on progression from adenoma to carcinoma, but did not vary significantly within the separate adenoma and carcinoma groups.
In summary, $\mathrm{p} 53$ is expressed in some adenomas, this expression increases substantially on progression to carcinoma and is independent of metastases. CD44 expression is maximal in adenomas, diminishes on progression to carcinoma and is further diminished in metastatic carcinoma. Determination of CD44 expression in the colorectum is of limited use as a screening test as CD44 is expressed in normal tissue. Determination of both CD44 and $\mathrm{p} 53$ expression, however, may prove useful in assessing which patients with adenomas are at greatest risk of progressing to cancer and who would therefore benefit from intensive surveillance. A study is currently underway to test this hypothesis.

We thank GUTS (Guildford Undetected Tumour Survey) and Marshall's (Godalming) for financial support through their charitable trusts and the Imperial Cancer Research Fund for the p53 antibody. We also thank R J B King for helpful discussion.

1 Heider KH, Horst E, van den Berg F, Hofman M, Porta $M$, Herrlich $\mathrm{P}$, et al. A human homologue of the rat metastasis associated variant of CD44 is expressed in colorectal carcinomas and adenomatous polyps. 7 Cell Biol 1993;120:227-33.

2 Fox SB, Gatter KC, Jackson DG, Scerton GR, Bell MV, et al. CD44 and cancer screening. Lancet 1993;342:548-9.

3 Tanabe KK, Ellis LM, Saya H. Expression of CD44 Rl adhesion molecule in colon carcinomas and metastases. Lancet 1993;341:725-6.

4 Wielenga VJM, Heider KH, Offerhaus GJA, Adolf GR, van der Berg FM, Ponta M, et al. Expression of CD44 variant proteins in human colorectal cancer is related to tumour progression. Cancer Res 1993;53:4754-6.

5 Abasi AM, Chester KA, Talbot IC, MacPherson AS, Boxer $\mathrm{G}$, Forbes $\mathrm{A}$, et al. CD44 is associated with proliferation in normal and neoplastic human colorectal epithelial cells. in normal and neoplastic human col

6 Mulder JWR, Weilenga VJM, Polak MM, van der Berg FM, Adolf GR, Herrlich P, et al. Expression of mutant p53 protein and CD44 variant proteins in colorectal tumorigenesis. Gut 1995;36:76-80.

7 Scott N, Bell SM, Sagar P, Blair GE, Dixon MF, Quirke P. p53 expression and K-ras mutation in colorectal adenomas. Gut 1993;34:621-4.

8 Goh HS, Chan C-S, Khine K, Smith DR. p53 and behaviour of colorectal cancer. Lancet 1994;344:233-4.

9 Nathanson SD, Linden MD, Tender P, Zarbo RJ, Jacobsen G, Nelson LT. Relationship among p53, stage and prognosis of large bowel cancer. Dis Colon Rectum 1994;37: nosis of -34 .

10 Hamelin R, Laurent-Puig P, Olsschwang S, Jego N, Asselain B, Remuikos Y, et al. Associations of p53 mutations with short survival in colorectal cancer. Gastrenterology 1994; 106:42-8.

11 Sun XF, Carstensen JF, Zhang $H$, Stal $O$, Wingren S, Hatschek T, et al. Prognostic significance of cytoplasmic p53 oncoprotein in colorectal adenocarcinoma. Lancet 1992;340:1369-73.

12 Chapuis PH, Dent OF, Fisher R, Newland RC, Pheils MT, Smyth E, et al. A multivariate analysis of clinical and pathological variables in prognosis after resection of large bowel carcinoma. Br f Surg 1985;72:698-702.

13 Wiggers T, Arends JW, Schutte B, Volovics L, Rosman FT. A multivariate analysis of pathological prognostic indicators in large bowel cancer. Cancer 1988;61:386-95.

indicators in large bowel cancer. Cancer 1988;61:386-95.
14 Fisher ER, Sass R, Palekar A, Fisher B, Wolmark N. Dukes classification revisited. Findings from the National Surgical Breast and Bowel Projects (Protocol R-01). Cancer 1989;64:2354-60.

15 Morson BC, Dawson IMP. Benign epithelial tumours. In: Gastrointestinal pathology. 3rd edn. Oxford: Blackwell Scientific Publications, 1990:567-8.

16 O'Brien MJ, Winawer SJ, Zauber AG, Gottleib LS, Sternberg SS, Diaz B, et al. The National Polyp Study. Patient and polyp characteristics associated with high-grade dysplasia in colorectal adenomas. Gastroenterology 1990;98: plasia in

17 Daas IO, Mulder J-WR, Offerhaus GJA, Yogelstein B, Hamilton SR. An evaluation of six antibodies for immunohistochemistry of mutant p53 gene product in munohistochemistry of mutant p53 gene product in

18 Fisher CJ, Gillett CE, Vojtëšek B, Barnes DM, Millis RR. Problems with p53 immunohistochemical staining: the effect of fixation and variation in the methods of evaluation. Br $\mathcal{F}$ Cancer 1994;69:26-31. 